August 1986

\title{
In Response: The Biological Basis and Treatment of Bulimia
}

Jeffrey M. Jonas, MD

Fair Oaks Hospital, Summit, New Jersey

Follow this and additional works at: https://jdc.jefferson.edu/jeffjpsychiatry

Part of the Psychiatry Commons

Let us know how access to this document benefits you

\section{Recommended Citation}

Jonas, MD, Jeffrey M. (1986) "In Response: The Biological Basis and Treatment of Bulimia," Jefferson Journal of Psychiatry. Vol. 4 : Iss. 2 , Article 13.

DOI: https://doi.org/10.29046/JJP.004.2.009

Available at: https://jdc.jefferson.edu/jeffjpsychiatry/vol4/iss2/13

This Article is brought to you for free and open access by the Jefferson Digital Commons. The Jefferson Digital Commons is a service of Thomas Jefferson University's Center for Teaching and Learning (CTL). The Commons is a showcase for Jefferson books and journals, peer-reviewed scholarly publications, unique historical collections from the University archives, and teaching tools. The Jefferson Digital Commons allows researchers and interested readers anywhere in the world to learn about and keep up to date with Jefferson scholarship. This article has been accepted for inclusion in Jefferson Journal of Psychiatry by an authorized administrator of the Jefferson Digital Commons. For more information, please contact: JeffersonDigitalCommons@jefferson.edu. 


\title{
In Response:
}

\section{The Biological Basis and Treatment of Bulimia}

\author{
Jeffrey M. Jonas, M.D.
}

The recent papers in the Jefferson Journal of Psychiatry by Drs. Levin ("Bulimia as a Masturbatory Equivalent," July, 1985) and Wilson ("A Discussion of 'Bulimia as a Masturbatory Equivalent',' Winter, 1986) contain a number of theories and recommendations about the etiology and treatment of bulimia which should be addressed. In large measure, both papers present a dynamic view of this disorder. However, psychodynamic formulations are but one of many theories put forward to explain this disorder. Other theories of etiology include notions that bulimia arises from cultural factors and an increased attention to body image, from disorders within the family as a whole, or from assorted behavioral factors which somehow reinforce binge-eating and purging.

One way to evaluate a theory of etiology is to ask whether treatments based upon a given theory benefit individuals with the disorder in question. For example, it would be of interest to know what evidence exists that individual psychotherapy is superior to group psychotherapy for the treatment of bulimia. Similarly it is important to know what empirical data underlie these theories. In the case of bulimia, as noted above, there are a host of ideas about what causes the disorder. And while a review of this literature is beyond the scope of this paper, at this time there is no systematic, controlled, non-anecdotal evidence that psychodynamic, behavioral, or cultural factors alone can lead to bulimia $(1,2)$.

In terms of treatment, we have a similar situation, where controlled studies of individual psychotherapy, group therapy, and behavior therapy are also lacking. There are numerous uncontrolled reports of the efficacy of these modalities in bulimic patients, but it is important to note why controlled studies are important in assessing treatments of this disorder. First, bulimia may remit spontaneously (1), so that a placebo group is needed to evaluate if a given therapy is effective. Second, bulimic patients may have amelioration of symptoms in structured settings. In assessing the first 40 consecutive inpatients

Jeffrey M. Jonas, M.D., is director of the Eating Disorders Program at Fair Oaks Hospital, Summit, New Jersey. 
admitted to the Fair Oaks Hospital Eating Disorders program, 33 had complete cessation of binging within the first 10 days. Such a response is misleading. At the end of two weeks (before treatment is completed) nearly two-thirds of the 33 "responders" will binge and purge on their first pass, and nearly all of the 33 "responders" will report urges to binge during the first two weeks. This kind of phenomenon points out the need for a control group, as well as follow-up information, before a given treatment can be said to be effective.

Given the prevalence of bulimia, there are relatively few studies of psychological and group treatments. One difficulty often cited in designing studies is that response to therapy cannot be assessed in a systematic manner. In bulimia, this is not the case. Bulimic patients have a number of overt symptoms which can be followed readily, such as the number of binge and purge episodes each day, severity of binge and purge urges, and severity of depression. Thus, there seems little reason why studies of therapeutic efficacy of various modalities could not be undertaken. Yet data supporting the use of many popular therapies are scanty at best. There are at this time no controlled studies of individual psychotherapy in bulimia beyond uncontrolled case series. Cognitive behavioral therapy has been reported successful in two uncontrolled studies $(3,4)$, whereas therapy has been reported useful in several uncontrolled reports (5-9).

We are not advocating that individuals with bulimia be deprived of group or individual therapy. Rather, we are pointing out that at this time there is little to commend one talking therapy from another. Recommendations for group and individual therapy should be made on an individual basis, rather than on the basis of diagnosis alone. In conjunction with such treatment, however, we must now address the use of a different therapeutic technique which appears applicable to this diagnostic category as a whole - the use of antidepressant medication.

The rationale for the use of antidepressants in bulimia comes from the body of evidence linking bulimia and anorexia nervosa to affective disorders. This evidence stems from three lines of research: studies of phenomenology, family history, and biological tests. Studies of phenomenology have examined groups of bulimic patients seeking treatment for their eating disorder. Such studies have consistently reported that bulimic patients have an increased lifetime prevalence of major depression and bipolar disorder, and that in up to 50 percent of cases the affective disorder antedates the onset of the eating disorder $(10-12)$. Studies of family history also suggest a biological link between affective disorders and bulimia, in that most but not all groups have reported an increased incidence of affective disorders in the families of patients with bulimia (13-15).

The third line of evidence linking eating disorders to affective disorders arises from studies of the dexamethasone suppression test (DST) and thyrotropin releasing hormone stimulation test (TRHST). Both the DST $(14,16,17)$ and TRHST (14) yield positive results in bulimia at rates comparable to those observed among individuals with depression. These results should be interpreted with caution, since metabolic stresses attributable to binging, purging, 
admitted to the Fair Oaks Hospital Eating Disorders program, 33 had complete cessation of binging within the first 10 days. Such a response is misleading. At the end of two weeks (before treatment is completed) nearly two-thirds of the 33 "responders" will binge and purge on their first pass, and nearly all of the 33 "responders" will report urges to binge during the first two weeks. This kind of phenomenon points out the need for a control group, as well as follow-up information, before a given treatment can be said to be effective.

Given the prevalence of bulimia, there are relatively few studies of psychological and group treatments. One difficulty often cited in designing studies is that response to therapy cannot be assessed in a systematic manner. In bulimia, this is not the case. Bulimic patients have a number of overt symptoms which can be followed readily, such as the number of binge and purge episodes each day, severity of binge and purge urges, and severity of depression. Thus, there seems little reason why studies of therapeutic efficacy of various modalities could not be undertaken. Yet data supporting the use of many popular therapies are scanty at best. There are at this time no controlled studies of individual psychotherapy in bulimia beyond uncontrolled case series. Cognitive behavioral therapy has been reported successful in two uncontrolled studies $(3,4)$, whereas therapy has been reported useful in several uncontrolled reports (5-9).

We are not advocating that individuals with bulimia be deprived of group or individual therapy. Rather, we are pointing out that at this time there is little to commend one talking therapy from another. Recommendations for group and individual therapy should be made on an individual basis, rather than on the basis of diagnosis alone. In conjunction with such treatment, however, we must now address the use of a different therapeutic technique which appears applicable to this diagnostic category as a whole-the use of antidepressant medication.

The rationale for the use of antidepressants in bulimia comes from the body of evidence linking bulimia and anorexia nervosa to affective disorders. This evidence stems from three lines of research: studies of phenomenology, family history, and biological tests. Studies of phenomenology have examined groups of bulimic patients seeking treatment for their eating disorder. Such studies have consistently reported that bulimic patients have an increased lifetime prevalence of major depression and bipolar disorder, and that in up to 50 percent of cases the affective disorder antedates the onset of the eating disorder (10-12). Studies of family history also suggest a biological link between affective disorders and bulimia, in that most but not all groups have reported an increased incidence of affective disorders in the families of patients with bulimia (13-15).

The third line of evidence linking eating disorders to affective disorders arises from studies of the dexamethasone suppression test (DST) and thyrotropin releasing hormone stimulation test (TRHST). Both the DST $(14,16,17)$ and TRHST (14) yield positive results in bulimia at rates comparable to those observed among individuals with depression. These results should be interpreted with caution, since metabolic stresses attributable to binging, purging, 
and weight loss could produce false positive results (18). However, studies of inpatient bulimics have shown that the rate of dexamethasone non-suppresion is not affected by hospitalization, even after binging and purging are controlled through milieu treatment $(16,19)$.

The evidence summarized above suggests a biological link between bulimia and the affective disorders. It should be noted that there are aspects of the eating disorders not explained by this linkage, such as the relationship of eating disorders and substance abuse (20). However, the affective model of eating disorders has led to an important treatment of bulimia, the use of antidepressant medication.

Numerous open-studies of antidepressants in bulimia have appeared in the literature since $1977(1,2)$, describing the use of heterocyclic antidepressants and monoamine oxidase inhibitors (MAOI's). Since then, five placebocontrolled, double-blind studies of heterocyclic antidepressants or MAOI's have been completed (21-25). One study using low dosages of mianserin had negative results (21), and one study using amitriptyline had weakly positive results (22). Both studies appeared to suffer from the use of inadequate dosages of antidepressant. The other three studies of antidepressants reported strongly positive findings. Pope et al. (23) observed a 70 percent reduction of binge-eating in patients taking imipramine in dosages up to $200 \mathrm{mg}$ each day, as compared to virtually no change in a placebo-control group. Significant reductions in depression, food preoccupation, and subjective global improvement were also noted. Walsh et al. had similarly positive results using phenelzine (23), as did Hughes et al. using desipramine (24). The study by Hughes and colleagues was of particular interest because they selected bulimic patients who did not display major depression. Despite this fact, Hughes' group found that $15(68 \%)$ of 22 subjects experienced a remission of their bulimic symptoms within ten weeks. Another important finding of the Hughes study was that plasma levels of desipramine comparable to those required in depression were required for response, and that dosages up to $350 \mathrm{mg}$ of desipramine were required to obtain adequate serum levels (125-275 ug/ml in their laboratory).

Overall, a growing body of evidence supports the use of antidepressant medication in the treatment of bulimia, whether or not the patient suffers from concomitant major depression. Follow-up data from the study of Pope et al. further support the utility of antidepressants (26). After one to two years on medication, 50 percent of patients were free of bulimic symptoms, 45 percent had a greater than 50 percent reduction of symptoms, and only one patient, who had discontinued medication, was unchanged. These promising data are tempered by the fact that complicated pharmacologic treatments were required in some cases in order to achieve maximal results. Nevertheless, a majority of these patients were able to return to full function, and did so without the aid of other ancillary therapies.

A number of caveats should be raised at this point. First, agents other than 
antidepressants have been useful in bulimia, including lithium (27), and methylamphetamine (28). Naltrexone has also been reported to be of use in these patients (29), but only on an open-label basis. In general, treatment with thymoleptics must be systematic and careful utilizing medication in adequate dosages for adequate periods of time, carefully monitoring serum levels (30).

Second, medication does not interfere with psychotherapy. If anything the cognitive improvement which patients experience when depression and food preoccupation lessen make them more amenable to therapy.

Third, the notion that patients should be allowed to "experience" their eating disorder in order to achieve insight should be considered as archaic and cruel as notions that antidepressants should be withheld from depressed individuals for like reasons. Such an approach is also medically dangerous, in light of the physical damage which may attend constant binging and purging. The role of treatment is to hasten recovery, and antidepressant therapy can help in this regard.

Finally, clinicians often misinterpret the use of antidepressants as a de facto statement against the use of psychotherapy. This is untrue. Many if not most patients with bulimia will have individual and family problems which require individual, group, and family psychotherapy. In our own treatment program, patients are engaged in all of these therapies, in addition to milieu, nutritional, and exercise therapy. In treating the whole patient, one needs to address biological as well as psychological needs. In so doing, the use of thymoleptics plays an important role. Given the evidence for the efficacy of antidepressants in bulimia, there is little reason to withhold them from patients with this disorder. [Ed.: For Dr. Wilson's reply, see the Letters to the Editor section.]

\section{REFERENCES}

1. Pope HG, Hudson JI: New Hope for Binge Eaters: Advances in the Understanding and Treatment of Bulimia. New York, Harper and Row: 1984

2. Pope HG, Hudson, Jonas JM, et al: Treatment of bulimia with antidepressants: A research update, in Physiology and Treatment of Normal Weight Women With Bulimia; Edited by Kaye W, Gwirtsman HE. Washington D.C.: American Psychiatric Association, 1985:120-131

3. Fairburn C: A cognitive behavioral approach to the treatment of bulimia. Psychol Med $11: 707-711,1981$

4. Schneider JA, Agras WS: A cognitive behavioral group treatment of bulimia. $\mathrm{Br} J$ Psychiatry 146:66-69, 1985

5. Boskind-Lodahl $\mathbf{M}$, White WC: The definition and treatment of bulimarexia in college women-a pilot study. J Am Coll Health Assoc 27:85-86, 1978

6. White WC, Boskind-White M. An experiential-behavioral approach to the treatment of bulimarexia. Psychotherapy: Theory, Research, and Practice. 1981; 4:501-507

7. Johnson CL, Connors M, Stuckey M: Short-term group treatment of bulimia: A preliminary report. Int J Eat Dis 2:199-208, 1983 
8. Lacey JG: Bulimia nervosa, binge eating, and psychogenic vomiting: A controlled treatment study and long-term outcome. Br Med J 286:1609-1613, 1983

9. Conners M, Johnson CL, Stuckey M: Treatment of bulimia with brief psychoeducational group therapy. Am J Psychiatry 141:1512-1516, 1984

10. Hudson JI, Pope HG, Jonas JM, et al: Phenomenologic relationship of eating disorders to major affective disorder. Psychiatry Res 9:345-354, 1983

11. Hatsukami DK, Eckert ED, Mitchell JE, et al: Affective disorder and substance abuse in women with bulimia. Psychological Medicine 14:701-704, 1984

12. Herzog DB: Are anorexic and bulimic patients depressed? Am J Psychiatry 141:15941597,1984

13. Hudson JI, Pope HG, Jonas JM, et al: Family history study of anorexia nervosa and bulimia. Br J Psychiatry 142:133-138, 1983

14. Gwirtsman H, Roy-Byrne P, Yager J, et al: Neuroendocrine abnormalities in bulimia. Am J Psychiatry 140:559-563, 1983

15. Steern SL, Dixon KN, Nezmer E, et al: Affective disorder in the families of women with normal-weight bulimia. Am J Psychtry 141:1224-1227, 1984

16. Hudson JI, Pope HG, Jonas JM, et al: Hypothalamic-pituitary-adrenal axis hyperactivity in bulimia. Psychiatry Res 8:111-117, 1983

17. Mitchell JE, Pyle RL, Hatsukami D, et al: The dexamethasone suppression test in patients with the bulimic syndrome. J Clin Psychiatry 45:508-51 1, 1984

18. Edelstein CK, Roy-Birne P, Fawzy FI, et al: Effects of weight loss on the dexamethasone suppression test. Am J Psychiatry 140:338-341, 1983

19. Kay WH, Gwirtsman HE, Ebert MH, et al: Neurobiology of binging and vomiting behavior. Presented at the Annual Meeting, American Psychiatric Association, May 10,1984

20. Jonas JM, Gold MS: Naltrexone treatment of bulimia: Clinical and theoretical findings linking eating disorders and substance abuse. Adv Alcohol and Substance Abuse (in press).

21. Sabine EJ, Yonace A, Farrington AJ, et al: Bulimia nervosa: A placebo-controlled double-blind therapeutic trial of mianserin. Br J Clin Pharmacol 15:195s-202s, 1983

22. Mitchell JE, Groat R: A placebo-controlled, double-blind trial of amitriptyline in bulimia. J Clin Psychopharm 4:186-193, 1984

23. Pope HG, Hudson JI, Jonas JM, et al: Bulimia treated with imipramine: A placebocontrolled double-blind study. Am J Psychiatry 140:554-558, 1983

24. Walsh BT, Stewart JW, Roose SP, et al: Treatment of bulimia with phenelzine: A double-blind, placebo-controlled study. Arch Gen Psychiatry 41:1105-1 109, 1984

25. Hughes PL, Wells LA, Cunningham CJ, et al: Treating bulimia with desipramine: A placebo-controlled double-blind study. Arch Gen Psychiatry 43:182-186, 1986

26. Pope HG, Hudson JI, Jonas JM, et al: Antidepressant treatment of bulimia: A two-year follow-up. J Clin Psychopharm 5:320-327, 1985

27. Hsu LKG: Treatment of bulimia with lithium. Am J Psychiatry 141:1260-1262, 1984

28. Ong YL, Checkely SA, Russell GFM: Suppression of bulimia symptoms with methylamphetamine. Br J Psychiatry 143:288-293, 1983

29. Jonas JM, Gold MS: Naltrexone reverses bulimic symptoms. Lancet 1:807, 1986

30. Pope HG, Hudson JI, Jonas JM: Antidepressant treatment of bulimia: Preliminary experience and practical recommendations. J Clin Psychopharmacology 3:274-281, 1983 